\title{
Multiple Myeloma Secondary to Systemic Lupus Erythematosus and Sjögren's Syndrome: A Case Report
}

\author{
Jia WANG, Xi XIE, Fen LI, Jinwei CHEN \\ Department of Rheumatology and Immunology, The Second Xiangya Hospital, Central South University, Changsha, China
}

Patients with rheumatic diseases are at an increased risk for malignant lymphoproliferative disease, but the coexistence of rheumatic diseases and multiple myeloma is uncommon. Herein, we report a rare case of systemic lupus erythematosus and Sjögren's syndrome, which preceded the development of multiple myeloma after three years. We also summarize the clinical features of this case and discuss the possible pathogenetic mechanisms that underlie this unusual association.

Keywords: Multiple myeloma; Sjögren's syndrome; systemic lupus erythematosus.

It is known that patients who are affected by rheumatic diseases like systemic lupus erythematosus (SLE) and Sjögren's syndrome (SS) are more prone to developing malignant lymphoproliferative disease, especially non-Hodgkin's lymphoma. In addition, SLE and SS are also associated with some plasma cell dyscrasias, such as monoclonal gammopathy of undetermined significance, macroglobulinemia, and amyloidosis; however, multiple myeloma (MM) as a lymphoproliferative neoplasm and plasma cell dyscrasia are not nearly as common. Herein, we present a female patient who developed MM three years after being diagnosed with SLE and SS.

\section{CASE REPORT}

A 47-year-old Chinese female came to our department on November $12^{\text {th }}$, 2011 because she had been suffering from chest and lumbar pain for three months. In 2008, she had been diagnosed with SLE and SS, which manifested with fatigue, alopecia, dry eyes and mouth, and swollen and painful joints. In addition, her laboratory findings had shown elevated protein levels and abnormal erythrocytes in the urine sediment at that time as well as high-titer antinuclear antibodies (ANAs), anti-nucleosome, anti-double-stranded DNA (antidsDNA), and anti-Ro/SS-A antibodies in the serum. Furthermore, the results of the Schirmer I test and the labial gland biopsy were positive. She was then started on a therapy regime that included steroids (prednisone $30 \mathrm{mg}$ daily), hydroxychloroquine (HCQ) (400 mg daily), and cyclophosphamide (800 mg monthly), and this relieved her symptoms. The patient continued to be routinely followed up, and the disease remained stable; thus, the prednisone dosage was decreased to $5 \mathrm{mg}$ /day in 2010. Three months prior to coming to our facility, she started feeling pain in her ribs and lumbar region which became exacerbated with movement. An evaluation of her past medical history revealed nothing out of the ordinary, although we determined 
that her mother had died of SLE. Additionally, a physical examination showed that her activities were limited by mild lumbar scoliosis, and she had tenderness on thoracic vertebrae 11 and 12 and lumbar vertebrae 2 and 4.

A laboratory investigation revealed a hemoglobin concentration of $62 \mathrm{~g} / \mathrm{L}$, a white blood cell (WBC) count of $3.3 \times 10^{9} / \mathrm{L}$, a total serum protein level of $110 \mathrm{~g} / \mathrm{L}$, and a globulin level of $74 \mathrm{~g} / \mathrm{L}$. Furthermore, a urinalysis determined that the concentration of red blood cells was 45,000 per $\mathrm{ml}$, with $65 \%$ being heterotypic, and the 24-hour urine protein excretion was $1.788 \mathrm{~g}$. The rest of her laboratory results, including the complement 3 (C3) levels and the results of the liver and renal function tests, were within normal limits. However, an autoimmune serology test was positive for ANA and antibodies to Ro/SS-A (+++) and Ro-52 (++) but negative for antibodies to dsDNA and Smith antigen.

Significant hypergammaglobulinemia was also noted (serum immunoglobulin G (IgG) $32.5 \mathrm{~g} / \mathrm{l}$, IgA $0.48 \mathrm{~g} / \mathrm{l}$, and $\operatorname{IgM}<0.18 \mathrm{~g} / \mathrm{l})$, and a serum immunoelectrophoretic analysis detected the presence of the kappa-type M protein. The kappa light chain

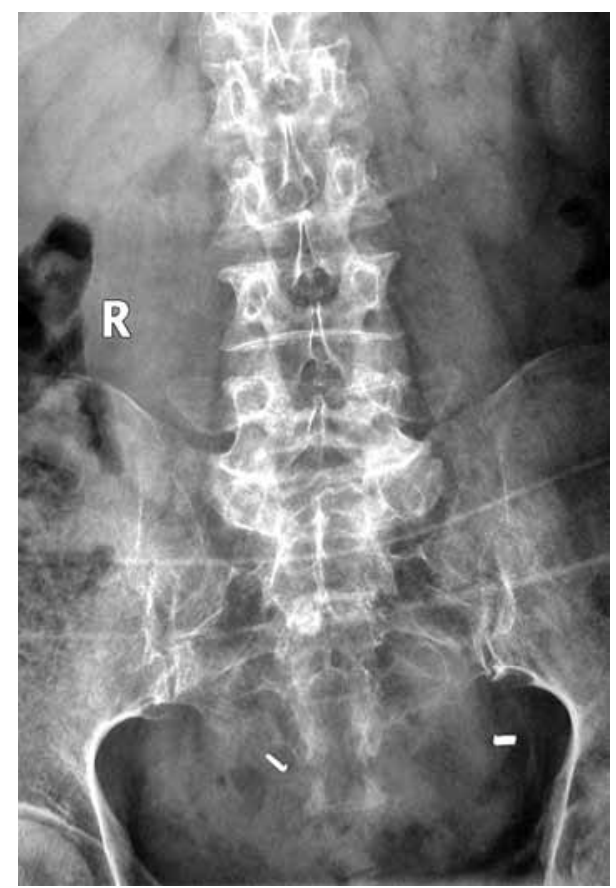

Figure 1. Osteoporosis and destruction of the pelvis along with the thoracic and lumbar vertebrae. type of Bence-Jones proteinuria was also noted. A biopsy and bone marrow aspiration were performed, and a marrow cytological examination showed a decrease in marrow hyperplasia with rouleau formation, but there was normal morphology of the red blood cells along with plasmacytosis (48\%). A pathological examination also revealed a similar result, confirming the diagnosis of MM. In addition, $\mathrm{X}$-rays detected serious osteoporosis and destruction of the pelvis, thoracic vertebrae, and lumbar vertebrae, together with compression fractures of thoracic vertebrae 11 and 12 and lumbar vertebrae 2 and 4 (Figure 1). Moreover, computed tomography showed a lumpy, highly dense shadow in the right hilum and scattered small nodules in the left lung (Figure 2). The patient was then transferred to the Department of Hematology where she underwent chemotherapy with vincristine, doxorubicin, and dexamethasone. Unfortunately, during the third cycle of chemotherapy, the patient died from severe pneumonia.

\section{DISCUSSION}

The association of SLE and MM has been described sporadically in the literature, but the possible pathogenetic mechanisms have not yet been elucidated. ${ }^{1-14}$ The pathogeneses of SLE and SS are similar, suggesting that aberrations in $\mathrm{T}$ and B cells could lead to polyclonal B cell hyperactivity, hyperglobulinemia, and autoantibody production. However, none of the cases of SLE and MM in the

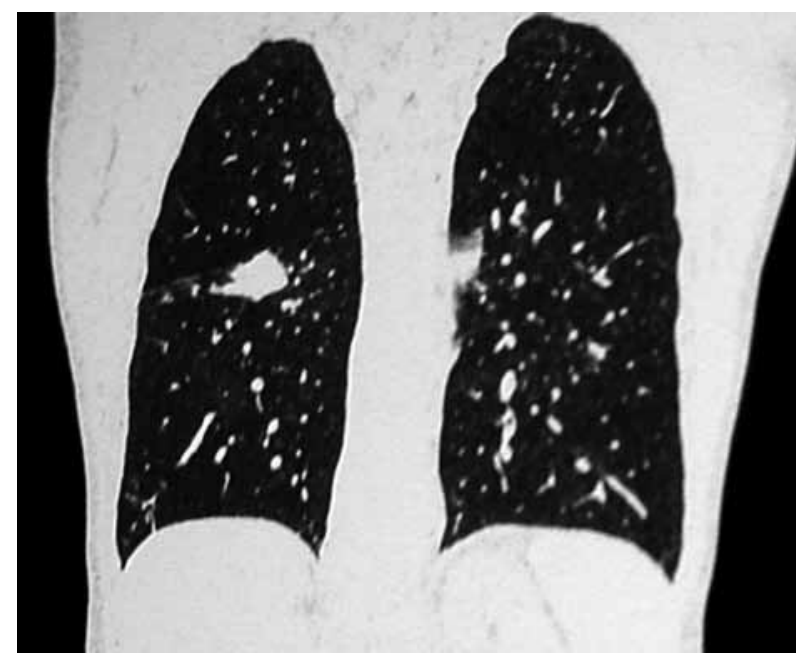

Figure 2. Lumpy, highly dense shadow in the right hilum and scattered small nodules in the left lung. 
literature were diagnosed with $\mathrm{SS}$, and only one case $^{14}$ mentioned Ro/SS-A and Ro-52 antibody positivity in the autoimmune serological test. Therefore, to our knowledge, this is the first case to be reported featuring the coexistence of $\mathrm{MM}$, SLE, and SS.

One important feature of this case was that the SLE had been quiescent, and the anti-dsDNA autoantibodies turned negative when the patient developed MM. However, the tests for Ro/SS-A and Ro-52 remained positive, with dry mouth and dry eyes seen during the entire course of the disease. It is well known that the anti-dsDNA autoantibody is present in some rheumatic diseases and that it is associated with disease activity and progression. Furthermore, this autoantibody has also been linked to lymphoproliferative disorders, such as B-cell chronic lymphocytic leukemia and MM. An interesting study by $\mathrm{Lu}$ et al. ${ }^{15}$ investigated the effects of anti-dsDNA autoantibodies on the growth of SP2/0 myeloma cells and Wehi-164 fibrosarcoma cells in vitro and in vivo and found that the autoantibodies had an inhibitory effect on these two kinds of tumor cells via the induction of apoptosis. They also indicated that a link exists between tumor immunity and autoimmunity.

Another feature of our case was that the patient's mother had died from SLE. A populationbased case-control study by Landgren et al. ${ }^{16}$ reported that the risk for MM was significantly elevated among individuals with a family history of SLE (OR=2.66; 95\% CI=1.12-6.32), and in a matched case control study of 8,406 MM patients by Miranda-Duarte et al., ${ }^{17}$ two patients had a personal history of SS while one had family history of SS. Furthermore, they suggested that there was an association between HLA class II and the probability of developing a malignancy in patients suffering from rheumatic diseases. Additionally, gene factor may also be one of the causes of rheumatic diseases and MM.

Monoclonal hyperglobulinemia is a popular cause of concern in patients with MM secondary to SLE. However, a large population-based study by Lindqvist et al. ${ }^{18}$ indicated that this occurs more frequently in rheumatic disease patients than in the general population, but this did not apply to MM. Moreover, another prospective study ${ }^{19}$ that focused on monoclonal gammopathy in SLE showed that no patient progressed to MM during the five-year study. Hence, it appears that there is no association with monoclonal hyperglobulinemia in patients with SLE and MM. However, the association between rheumatic diseases and MM needs further investigation.

\section{Conclusion}

Based on a previous literature review and the findings in this case, patients with rheumatic diseases have an increased incidence of malignancy. The reason for this may be related to immunological and genetic factors. However, this study lacks the evidence to prove this hypothesis; therefore, further clinical studies are needed.

\section{Declaration of conflicting interests}

The authors declared no conflicts of interest with respect to the authorship and/or publication of this article.

\section{Funding}

The authors received no financial support for the research and/or authorship of this article.

\section{REFERENCES}

1. Canoso JJ, Cohen AS. Malignancy in a series of 70 patients with systemic lupus erythematosus. Arthritis Rheum 1974;17:383-90.

2. Jordan E, Burnstein SL, Calabro JJ, Henderson ES. Multiple myeloma complicating the course of seronegative systemic lupus erythematosus. Arthritis Rheum 1978;21:260-5.

3. Pehamberger H, Diem E, Konrad K. Systemic lupus erythematosus with multiple myeloma. Acta Derm Venereol 1978;58:527-30.

4. Butler RC, Thomas SM, Thompson JM, Keat AC. Anaplastic myeloma in systemic lupus erythematosus. Ann Rheum Dis 1984;43:653-5.

5. Solary E, Caillot D, Guy H, Olsson NO, Tanter Y, Chalopin JM. Systemic lupus erythematosus occurring in a patient with multiple myeloma. Arthritis Rheum 1986;29:933-4.

6. Sendagorta E, Matarredona J, Brieva JA, Rodríguez ML, Ledo A. Systemic lupus erythematosus in association with smoldering multiple myeloma. J Am Acad Dermatol 1987;16:135-6.

7. Case records of the Massachusetts General Hospital. Weekly clinicopathological exercises. Case 30-1995. A 69-year-old woman with lupus erythematosus and painful skin lesions of the feet. $\mathrm{N}$ Engl J Med 1995;333:862-8. 
8. Afeltra A, Amoroso A, Garzia P, Addessi MA, Pulsoni A, Bonomo L. Systemic lupus erythematosus and multiple myeloma: a rare association. Semin Arthritis Rheum 1997;26:845-9.

9. Lee SJ, Lee SS, Kim YA, Park MJ, Lee JJ, Kim HJ. A Case of Multiple Myeloma in a Patient with Systemic Lupus Erythematosus. J Korean Rheum Assoc 2002;9:325-9.

10. Vaiopoulos G, Konstantopoulos K, Mantzourani M, Kaklamanis P. Multiple myeloma associated with systemic lupus erythematosus. Leuk Lymphoma 2003;44:893-4.

11. Urba ska-Ry H, Robak E, Kordek R, Bartkowiak J, Rieske $\mathrm{P}$, Wo niacka $\mathrm{A}$, et al. Multiple myeloma in a patient with systemic lupus erythematosus, myasthenia gravis and non-familial diffuse palmoplantar keratoderma. Leuk Lymphoma 2004;45:1913-8.

12. Bila J, Suvajdzic N, Elezovic I, Colovic M, Boskovic D. Systemic lupus Erythematosus and $\operatorname{IgA}$ multiple myeloma: a rare association? Med Oncol 2007;24:445-8.

13. Maamar M, Tazi Mezalek Z, Harmouche H, Adnaoui M, Aouni M, Maaouni A. Systemic lupus erythematosus and multiple myeloma: an uncommon association. Two cases and literature review. Clin Exp Rheumatol 2008;26:667-70.
14. Choi JW, Han SW, Kwon KT, Kim GW. Early onset multiple myeloma in a patient with systemic lupus erythematosus: a case report and literature review. Clin Rheumatol 2010;29:1323-6.

15. Lu S, Zhang JP, Wu HS, Zheng XJ, Chu YW, Xiong SD. Anti-tumor effect of anti-dsDNA autoantibodies. Zhonghua Zhong Liu Za Zhi 2005;27:73-6.

16. Landgren O, Linet MS, McMaster ML, Gridley G, Hemminki K, Goldin LR. Familial characteristics of autoimmune and hematologic disorders in 8,406 multiple myeloma patients: a population-based casecontrol study. Int J Cancer 2006;118:3095-8.

17. Miranda-Duarte A, Kraus-Weisman A, Granados J, Vill AR. Human leukocyte antigens class II genes are associated with cancer development in the autoimmune rheumatic diseases. Rev Invest Clin 2011;63:236-43

18. Lindqvist EK, Goldin LR, Landgren O, Blimark C, Mellqvist UH, Turesson I, et al. Personal and family history of immune-related conditions increase the risk of plasma cell disorders: a population-based study. Blood 2011;118:6284-91.

19. Ali YM, Urowitz MB, Ibanez D, Gladman DD. Monoclonal gammopathy in systemic lupus erythematosus. Lupus 2007;16:426-9. 